\title{
Ferroelectric property of an epitaxial lead zirconate titanate thin film deposited by a hydrothermal method
}

\author{
Takeshi Morita ${ }^{\text {a) }}$ and Yasuo Wagatsuma \\ Research Institute of Electrical Communication, Tohoku University, Miyagi 980-8577, Japan \\ Hitoshi Morioka and Hiroshi Funakubo \\ Department of Innovative and Engineered Materials, Tokyo Institute of Technology, \\ Yokohama 226-8502, Japan \\ Nava Setter \\ Ceramics Laboratory, Faculty of Engineering, Material Institute, Swiss Federal Institute of \\ Technology (EPFL), CH-1015 Lausanne, Switzerland \\ Yasuo Cho \\ Research Institute of Electrical Communication, Tohoku University, Miyagi 980-8577, Japan
}

(Received 7 January 2004; accepted 25 March 2004)

\begin{abstract}
Deposition of thin films via hydrothermal method has various advantages: low deposition temperature, high purity, deposition on a three-dimensional structure, and a large thickness. Although an epitaxial lead zirconate titanate (PZT) thin-film deposition has been reported, the ferroelectric measurement has not been conducted due to the peel-off morphology of the film. The current paper investigates the improvement of an epitaxial PZT thin film deposited via a hydrothermal method. By adjusting the position at which the substrate was suspended in the solution, smooth morphology surface was successfully obtained. As a bottom electrode, a 200-nm $\mathrm{SrRuO}_{3}$ thin film was deposited on $\mathrm{SrTiO}_{3}$ single crystals, and the PZT thin film was deposited on $\mathrm{SrRuO}_{3}$. The remanent polarization $2 \mathrm{Pr}$ and coercive electric field for PZT on $\mathrm{SrRuO}_{3} / \mathrm{SrTiO}_{3}(001)$ were $17.1 \mu \mathrm{C} / \mathrm{cm}^{2}$ and $36 \mathrm{kV} / \mathrm{cm}$, respectively, and those of PZT on $\mathrm{SrRuO}_{3} / \mathrm{SrTiO}_{3}(111)$ were $32.7 \mu \mathrm{C} / \mathrm{cm}^{2}$ and $59 \mathrm{kV} / \mathrm{cm}$, respectively. The reason for large imprint electrical field, $91 \mathrm{kV} / \mathrm{cm}$ and $40 \mathrm{kV} / \mathrm{cm}$ for each film, was unclear at this stage, although it is associated with self-alignment poling direction. This self-alignment poling direction was confirmed via scanning nonlinear dielectric microscopy and is thought to have been related to the deposition mechanisms.
\end{abstract}

\section{INTRODUCTION}

Epitaxial ferroelectric thin films, particularly lead zirconate titanate (PZT) epitaxial thin films, have intensively been studied for use in smart microelectrical mechanical systems (MEMS) and a ferroelectric random access memory (FeRAM) due to their large piezoelectric displacement and permanent polarization. ${ }^{1-3}$ Using a single-crystal substrate with a lattice constant close to that of PZT, the deposited film can be orientated according to the properties of the substrate. In an effort to obtain such a film, various film deposition processes have been explored, including sol-gel methods, sputtering methods, and chemical-vapor-deposition methods. ${ }^{4-6}$ However,

\footnotetext{
a) Address all correspondence to this author.

e-mail: tmorita@ieee.org

DOI: $10.1557 / J M R .2004 .0243$
}

with these methods, a high-temperature crystallization process (above $600{ }^{\circ} \mathrm{C}$ ) is required to achieve a PZT film.

The advantage of the hydrothermal method is low reaction temperature, less than $200{ }^{\circ} \mathrm{C}$. It is important to note that this temperature is below the Curie temperature of PZT and more than $400{ }^{\circ} \mathrm{C}$ below the reaction temperature required of other methods. Generally, a hightemperature procedure results in lead evaporation. This lead vacancy causes the generation of a subphase, such as a pyrochlore phase. Excess strain remains in the structure due to the phase change that occurs at the Curie temperature and the difference in the thermal expansion coefficient between PZT and the substrate. In some of the alternative deposition methods, a chemical reaction is carried out on the substrate; hence relict by-products might be observed in the ferroelectric films. On the other hand, using the hydrothermal method, the PZT thin film is synthesized directly as an ionic reaction in solution, 
making it possible to obtain a high-quality ferroelectric thin film.

When PZT is used as a transducer, the output force is proportional to the applied voltage, and maxim applied voltage increases as the PZT thickness increases. Therefore, a large thickness of the hydrothermal PZT film is a promising feature for developing a micro actuator driver.

The three-dimensional structure of deposited PZT films is an additional advantage of the hydrothermal deposition method. A PZT is synthesized in solution, so that the PZT thin film is deposited on all surfaces of the substrate. Such a three-dimensional structure is advantageous not only for actuators but for FeRAM applications. In an effort to realize higher memory density, a practical capacitor unit area is decreasing and detective charge is becoming more limited due to the small capacitor value. The concept of a three-dimensional capacitor can successfully overcome this obstacle, and the hydrothermal method may contribute to construction of this type of ferroelectric capacitor.

In 1991, Shimomura et al. reported that titanium metal is available as a substrate for a polycrystalline PZT thin film deposition. ${ }^{7}$ The deposition process was carried out with a successive nucleation and crystal-growth process. The scanning electron microscopy (SEM) observation verified the deposited film was composed of randomly oriented cubic-shaped crystals. An interesting feature of this film was the self-poling behavior it exhibited, which meant that no poling treatment was required. This hydrothermal process was later improved upon by Morita et al., making it a single-step process. ${ }^{8}$ Films obtained using this process were a few micrometers in thickness and used a three-dimensional titanium metal substrate; therefore, these PZT films were used as the drivers for micro ultrasonic motors and a tactile sensors. ${ }^{9-11}$

Chien et al. ${ }^{12}$ adopted a $\mathrm{SrTiO}_{3}$ single crystal (100) as the substrate for epitaxial PZT deposition using the hydrothermal method. X-ray diffraction (XRD) measurements revealed that an epitaxial PZT was obtained; however, both the (001) and (100) peaks were detected. Their proposed method suggested the possibility of a highquality PZT thin film. Unfortunately, electrical measurements for ferroelectric properties were unable to be conducted due to the lack of conductivity of a $\mathrm{SrTiO}_{3}$ substrate. Oledzka et al. later reported an epitaxial PZT thin film with some zirconium and titanium ion sources at various $\mathrm{KOH}$ concentrations and investigated the influence on the PZT lattice constant and the weight gain. ${ }^{13}$ While this research was advanced, one significant shortcoming was the peeled-off morphology of the epitaxial hydrothermal PZT thin film. ${ }^{13}$ This defect made it impossible to measure the fer-roelectric property of the film. In this work, the improved surface morphology of PZT films and the successful measurements of the ferroelectric properties are reported.

\section{EXPERIMENTAL}

\section{Improvement of surface morphology}

A peeled-off surface morphology is unsuitable for measuring the ferroelectric or piezoelectric performance, because the top electrode on such a film results in the electrical breakdown at the bottom electrode. We assumed the position of the substrate in the pressure vessel is a crucial parameter to improve surface morphology.

Before confirming our hypothesis, Chien's reaction conditions were tested using a $\mathrm{SrTiO}_{3}$ single crystal (100) as a control. The reaction conditions are listed in Table I. The pressure vessel (Parr Model, 4744, Illinois) consisted of an inner Teflon reaction vessel with a 26.4-mm diameter and maximum volume of $45 \mathrm{ml}$. After mixing the reactants, a single-crystal substrate was placed directly into the reaction vessel, and, similar to the procedure reported by Oledzka et al., the substrate was kept at the bottom of the reaction vessel. The reaction vessel was placed into a preheated $150{ }^{\circ} \mathrm{C}$ heater.

Next, in an effort to confirm our hypothesis, the relationship between position of the substrate and surface morphology was studied. A $\mathrm{SrTiO}_{3}$ substrate, $5.0-\mathrm{mm}$ wide, $0.5-\mathrm{mm}$ thick, and $15-\mathrm{mm}$ long, was fixed perpendicular to the bottom of a Teflon plate with a groove to place the substrate in, as shown in Fig. 1. The $\mathrm{SrTiO}_{3}$ clipped to the Teflon plate was placed into the Teflon reaction vessel. All of the other reaction conditions, with the exception of the holding position, were held constant with respect to the verified experiments. After the deposition process, the substrate was removed from the reaction vessel and observed using both an optical and a scanning electron microscope.

\section{BOTTOM ELECTRODE AND FERROELECTRIC PROPERTIES MEASUREMENTS}

To measure the ferroelectric properties, the bottom electrode is indispensable in applying the electrical field. $\mathrm{SrRuO}_{3}$ is a good candidate for the bottom electrode due to the lattice constant matching PZT and the good conductivity. The hydrothermal method uses $\mathrm{KOH}$, and so it is necessary to confirm that $\mathrm{SrRuO}_{3}$ electrode can withstand such a high alkali concentration. $\mathrm{A} \mathrm{SrRuO}_{3}$ film was rf-sputtered on the $\mathrm{SrTiO}_{3}$ substrate based on the conditions reported by Funakubo et al. ${ }^{14}$ Sputtering conditions are listed in Table II. On this $\mathrm{SrRuO}_{3}$ bottom

TABLE I. Reaction conditions for an epitaxial PZT thin film. ${ }^{12}$

\begin{tabular}{lc}
\hline \hline $\mathrm{Pb}\left(\mathrm{NO}_{3}\right)_{2}$ & $2.26 \mathrm{~g}$ \\
$\mathrm{ZrOCl}_{2} \cdot 8 \mathrm{H}_{2} \mathrm{O}$ & $0.78 \mathrm{~g}$ \\
$\mathrm{TiO}_{2}$ (anatase) & $0.20 \mathrm{~g}$ \\
$\mathrm{KOH}$ & $10 \mathrm{~N} 15 \mathrm{ml}$ \\
Temperature & $150^{\circ} \mathrm{C}$ \\
\hline
\end{tabular}




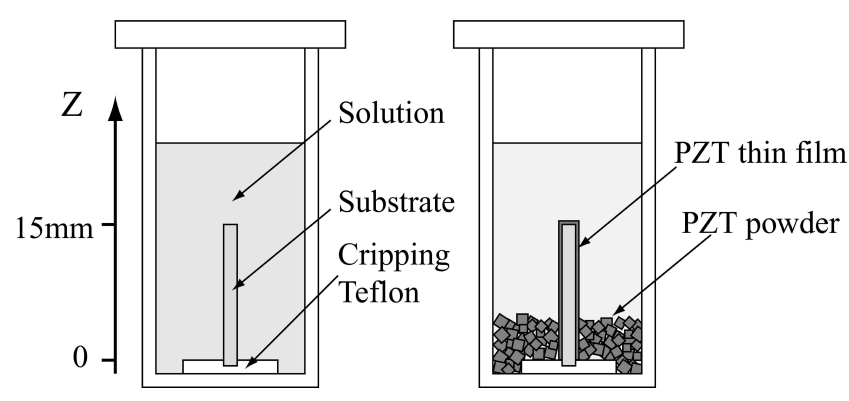

FIG. 1. A fixture suspending a $\mathrm{SrTiO}_{3}$ single-crystal substrate perpendicular to examine the film surface morphology dependence against the depth in the solution.

TABLE II. Radiofrequency magnetron sputtering.

\begin{tabular}{lc}
\hline \hline Temperature & $570^{\circ} \mathrm{C}$ \\
Pressure & $0.1 \mathrm{~Pa}$ \\
Gas & $\mathrm{Ar}+\mathrm{O}_{2}(60: 40)$ \\
rf power & $60 \mathrm{~W}$ \\
Time & $1 \mathrm{~h}$ \\
Thickness & $200 \mathrm{~nm}$ \\
\hline \hline
\end{tabular}

electrode, the PZT thin film was deposited. The special holding component was made of Teflon, and the substrate was maintained horizontally at $8.6 \mathrm{~mm}$ above the bottom in the Teflon reaction vessel, as shown in Fig. 2. After the hydrothermal reaction, the substrate was dried at $200{ }^{\circ} \mathrm{C}$ for $1 \mathrm{~h}$ under atmospheric pressure conditions.

A platinum top electrode was formed by vacuum evaporation using a metal mask. The thickness of the top electrode was $100 \mathrm{~nm}$ and its area was $0.083 \mathrm{~mm}^{2}$. The ferroelectric performance was investigated with a PE hysteresis curve, and a scanning nonlinear dielectric microscope (SNDM). The polarization electric field (PE) hysteresis curve was measured at $1 \mathrm{kHz}$. The SNDM is a powerful tool for detecting the poling direction distribution on the subnanometer scale. ${ }^{15}$ In many cases, SNDM

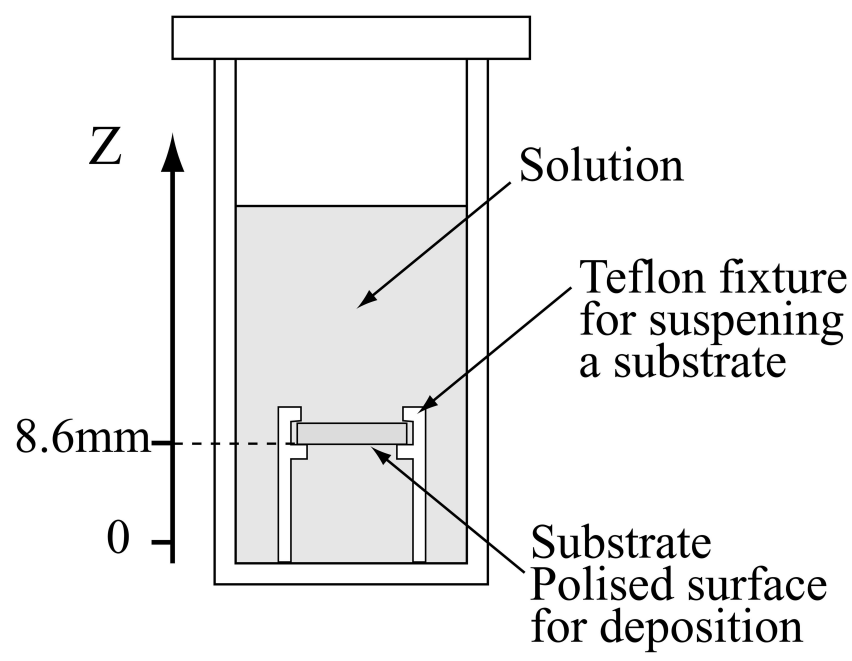

FIG. 2. A special holding component to obtain smooth surface PZT. The depth was $8.6 \mathrm{~mm}$ from the bottom of the inner reaction vessel, and the polished surface of the single crystal was faced to the bottom.

observation has been used to verify the presence of nonferroelectric materials in ferroelectric films, even with large remanent polarization value, on the nanometer scale. With respect to practical application, such nonferroelectric materials are a serious disadvantage.

\section{RESULTS AND DISCUSSION Improvement of surface morphology}

To accurately measure the ferroelectric properties of a hydrothermal PZT thin film, a smooth surface morphology of the film is imperative. Chien's reaction conditions were tested using a $\mathrm{SrTiO}_{3}$ single-crystal (100) as a control. After $3 \mathrm{~h}$, the $\mathrm{SrTiO}_{3}$ substrate was removed and carefully washed with distilled water. Oledzka et al. reported that the deposited film contained cracks and had a
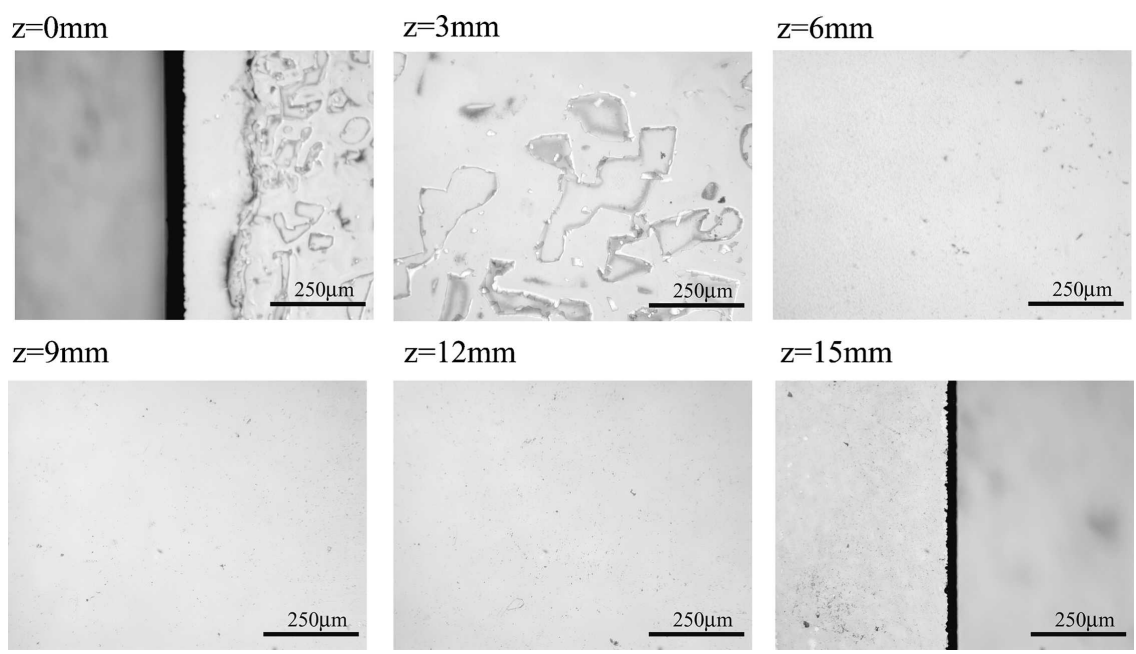

$\mathrm{z}=12 \mathrm{~mm}$

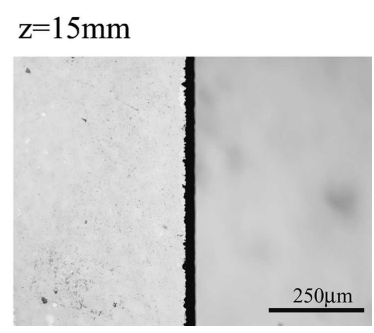

FIG. 3. Optical microscope observation results about the PZT film morphology at the various depths. 

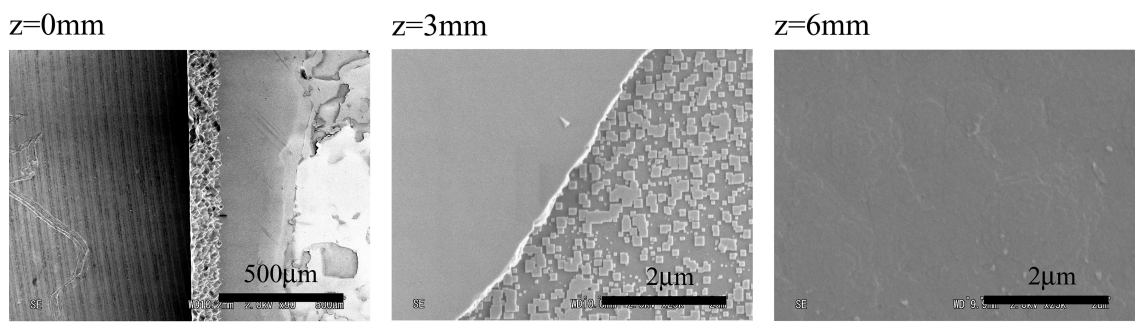

$\mathrm{z}=9 \mathrm{~mm}$

$\mathrm{z}=12 \mathrm{~mm}$

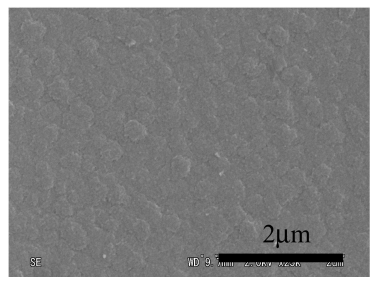

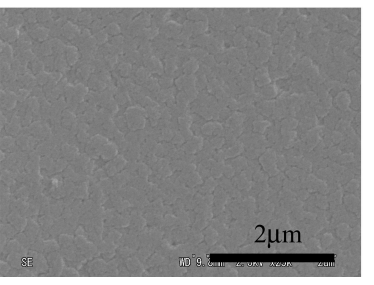

$\mathrm{z}=15 \mathrm{~mm}$

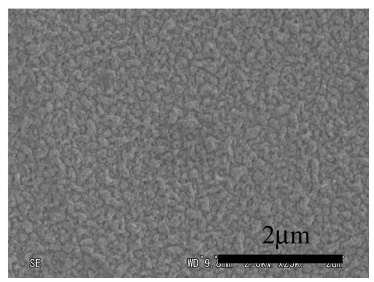

FIG. 4. Scanning electron microscope observation results about the PZT film morphology at the various depths.

peeled-off morphology after the substrate had been reacted for $24 \mathrm{~h}^{13}$ Similarly, here, the substrate was observed to contain cracks and have a peeled-off morphology after only $3 \mathrm{~h}$. A smooth surface morphology of the film could not be achieved by modifying the reaction conditions such as the reaction temperature and the concentration of the reactants in solution.

The position at which the substrate was held in the reaction vessel was considered to be the crucial condition. In the previously reported deposition, the substrate was probably kept at the bottom of the reaction vessel, as described in the confirmed procedure. The surface morphology at each position from the bottom is shown in Fig. 3 (optical microscope images) and Fig. 4 (SEM images). From the images, it is clear that when reacted in the region from the bottom of the vessel to $6 \mathrm{~mm}$ above the bottom of the vessel, the surface morphology of the film was observed to peel off. This result was consistent with that of both the control experiment and Oledzka's report. $^{13}$

When the substrate was held at a depth of 6 to $11 \mathrm{~mm}$ during deposition, the resultant film surface was smooth, and SEM images confirmed that there were no cracks on the micrometer scale. At deposition heights greater than $11 \mathrm{~mm}$, the surface was not peeled off, but was observed to be uneven. The deposition boundary between a peeling and smooth surface morphology was evident; therefore, the origin of the peeling can be explained. PZT powder is synthesized as a side-product of the hydrothermal method for thin-film deposition. If the substrate is placed at the bottom of the reaction vessel, as was done with the previous study, the PZT thin film makes contact with the PZT powder during the reaction. This contact is thought to cause an uneven concentration around the substrate, resulting in an uneven and peeling morphology of the deposited PZT thin film. The uneven surface on the upper layer of the PZT thin film indicated that the chemical concentration was not uniform. This weak chemical concentration resulted in a decreased deposition force. These findings revealed that the optimum depth for smooth surface is from $6 \mathrm{~mm}$ to $11 \mathrm{~mm}$.

The thickness as a function of depth was measured within this range. The PZT thickness was measured using SEM observation of the cross section. As expected from surface observation, the PZT thickness increased linearly from the bottom to the top, as shown in Fig. 5.

\section{FUNDAMENTAL PROPERTIES AND FERROELECTRIC MEASUREMENT RESULTS}

XRD measurement indicated that the $\mathrm{SrRuO}_{3}$ film was epitaxially deposited on the $\mathrm{SrTiO}_{3}$ at a thickness of $200 \mathrm{~nm}$. The $\mathrm{SrTiO}_{3}$ substrate with a $\mathrm{SrRuO}_{3}$ bottom electrode was used for the hydrothermal deposition. The crystal orientations were (100) and (111). The reaction conditions were identical to the previous reaction conditions except for the holding position. The obtained PZT

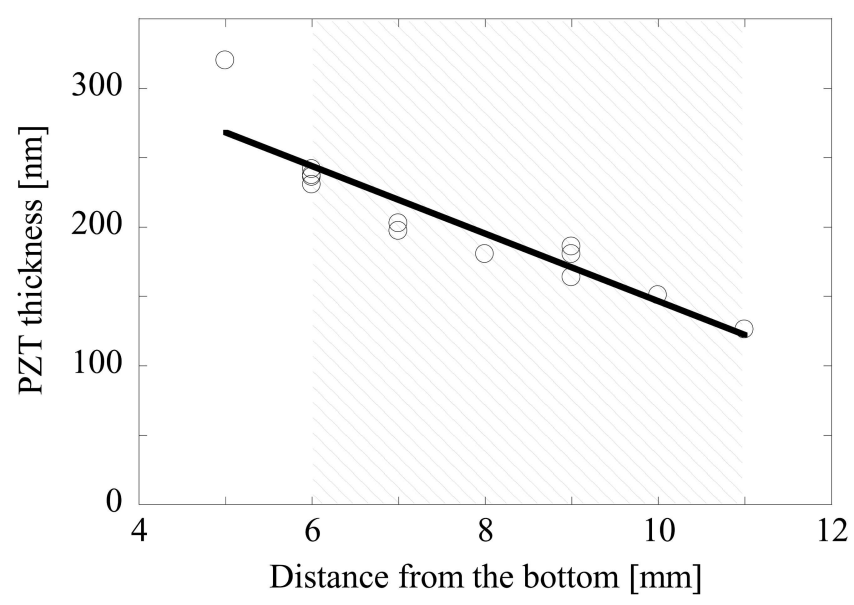

FIG. 5. A relationship between the PZT thickness and depth in the solution. 

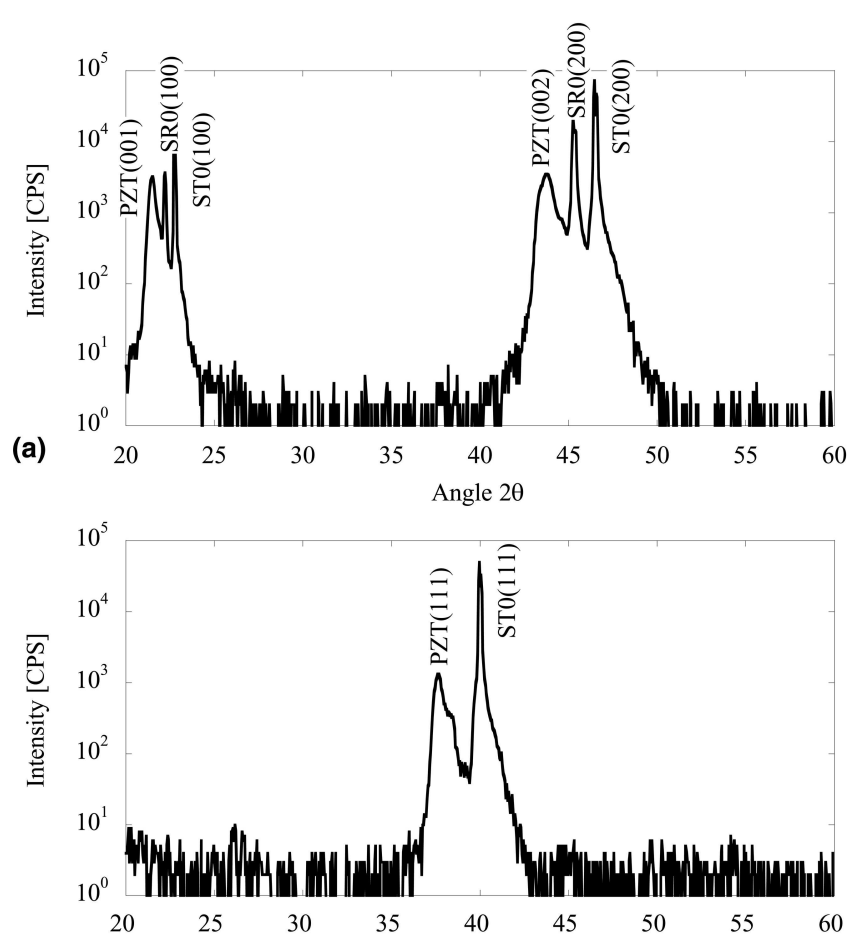

(b)

FIG. 6. Results of XRD measurements for PZT thin films on (a) (100) $\mathrm{SrRuO}_{3} / / \mathrm{SrTiO}_{3}$ and (b) (111) $\mathrm{SrRuO}_{3} / / \mathrm{SrTiO}_{3}$.

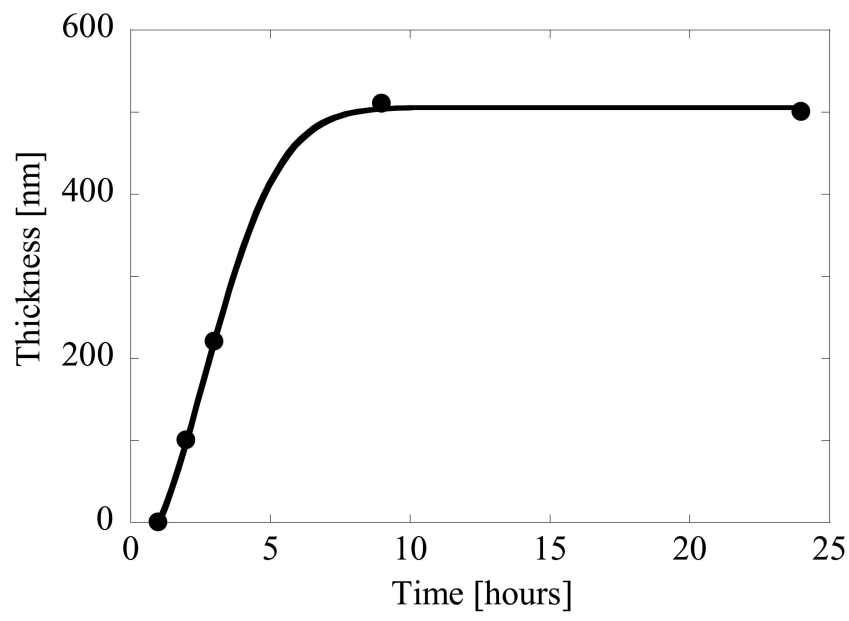

FIG. 7. A relationship between the PZT thickness and the reaction time.

thin film was transparent, and some interference fringes were observed outside the substrate. As depicted in Fig. 6, XRD measurements indicated that the PZT thin film was epitaxially oriented to the $\mathrm{SrTiO}_{3}$ substrate and there was no second phase, as is the case with a pyrochlore. The results of the (111) PZT, (111) $\mathrm{SrRuO}_{3}$ peak was hidden in the strong $\mathrm{SrTiO}_{3}$ peak. However, as shown later, using this PZT, a hysteresis curve could be measured, which indicates that the $\mathrm{SrRuO}_{3}$ bottom

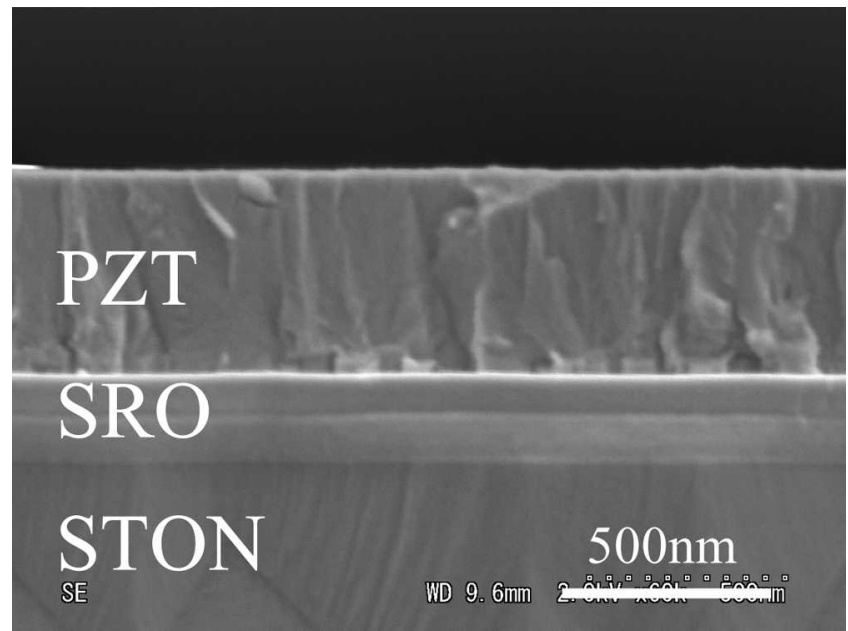

FIG. 8. Cross section of the deposited PZT thin film on the $\mathrm{SrRuO}_{3} / / \mathrm{SrTiO}_{3}$ (100) substrate. The reaction time was $9 \mathrm{~h}$.

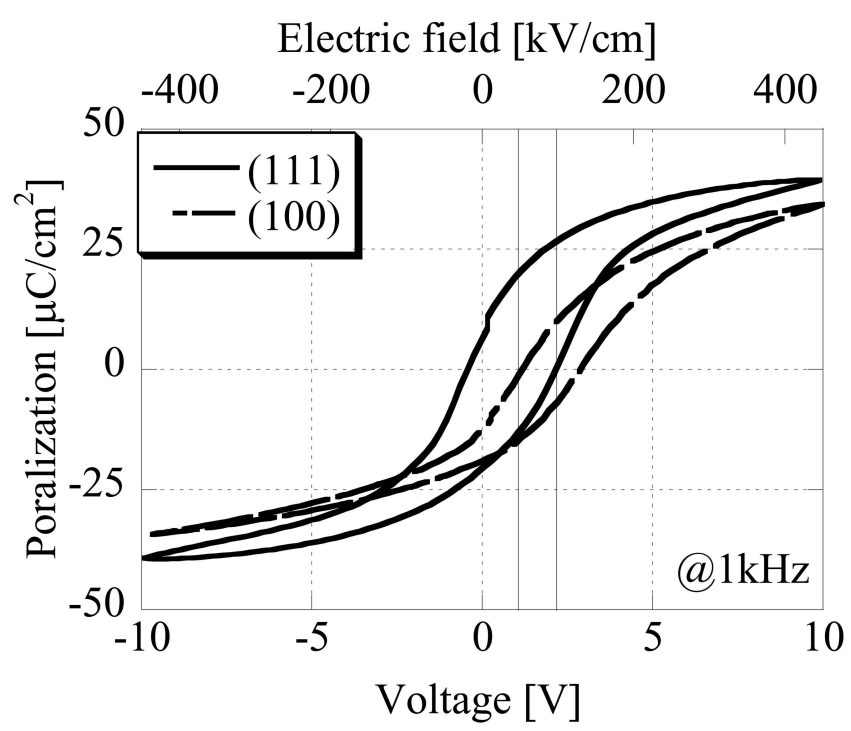

FIG. 9. Hysteresis curves for PZT thin films on $\mathrm{SrRuO}_{3} / / \mathrm{SrTiO}_{3}(100)$ and $\mathrm{SrRuO}_{3} / \mathrm{SrTiO}_{3}(111)$.

TABLE III. Ferroelectric parameters obtained by PE hysteresis curve.

\begin{tabular}{cc}
\hline \hline PZT on (100) SRO/STO & \\
$+\mathrm{Pr}$ & $9.2 \mu \mathrm{C} / \mathrm{cm}^{2}$ \\
$-\mathrm{Pr}$ & $-7.9 \mu \mathrm{C} / \mathrm{cm}^{2}$ \\
Ec & $36 \mathrm{kV} / \mathrm{cm}^{2}$ \\
Imprint & $91 \mathrm{kV} / \mathrm{cm}$ \\
$\mathrm{PZT}$ on $(111) \mathrm{SRO} / \mathrm{STO}$ & \\
$+\mathrm{Pr}$ & $18.8 \mu \mathrm{C} / \mathrm{cm}^{2}$ \\
$-\mathrm{Pr}$ & $-13.9 \mu \mathrm{C} / \mathrm{cm}^{2}$ \\
Ec & $59 \mathrm{kV} / \mathrm{cm}^{2}$ \\
Imprint & $40 \mathrm{kV} / \mathrm{cm}$ \\
\hline \hline
\end{tabular}

electrode existed. The PZT film orientation implied that this bottom electrode was oriented to (111) $\mathrm{SrTiO}_{3}$. A lattice constant tangential to the substrate was calculated to be $0.4134 \mathrm{~nm}$ for (001). From a (111) PZT peak, 


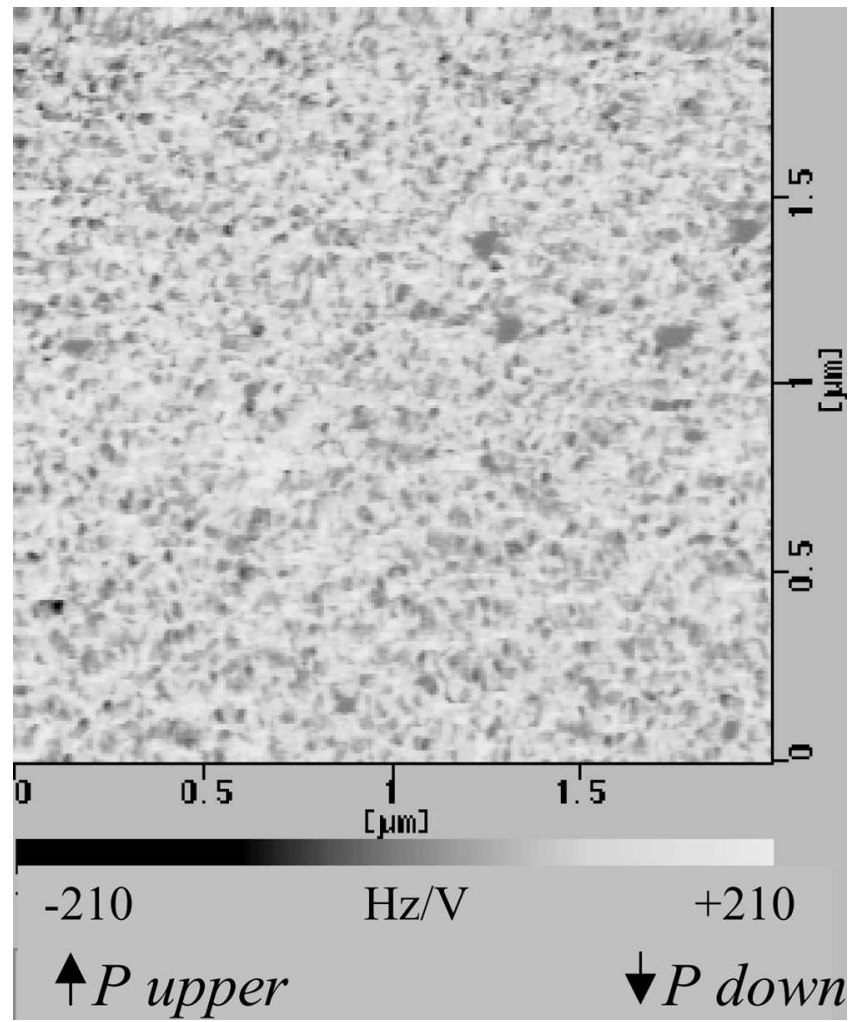

FIG. 10. An observation results of the PZT on $\mathrm{SrRuO}_{3} / / \mathrm{SrTiO}_{3}(100)$ using a scanning nonlinear dielectric microscopy. This result indicates the poling direction was aligned from the surface to the bottom substrate.

$0.7164 \mathrm{~nm}$ of unit lattice direction (111) and $0.4136 \mathrm{~nm}$ is calculated if the crystal is considered to be cubic just for reference.

When the chemical reaction is completed, the precipitation and dissolution are counterbalanced. Hence, after a certain time, the film thickness is saturated similar to a polycrystalline PZT deposition on titanium substrate. As shown in Fig. 7, the thickness of the PZT thin film after $3 \mathrm{~h}$ was $220 \mathrm{~nm}$ and that after $24 \mathrm{~h}$ was $500 \mathrm{~nm}$. The saturation time is approximately $9 \mathrm{~h}$ under these reaction conditions. The SEM cross section of the film deposited after $9 \mathrm{~h}$ is shown in Fig. 8, which indicates a high-purity PZT thin film. A close-packed film was obtained.

The hysteresis curve shown in Fig. 9 is the first result of the hydrothermally deposited PZT thin film. The remanent polarization $2 \mathrm{Pr}$ and coercive electric field for PZT on $\mathrm{SrRuO}_{3} / \mathrm{SrTiO}_{3}(001)$ were $17.1 \mu \mathrm{C} / \mathrm{cm}^{2}$ and $36 \mathrm{kV} / \mathrm{cm}$, respectively, and those of $\mathrm{PZT}$ on $\mathrm{SrRuO}_{3} / \mathrm{SrTiO}_{3}(111)$ were $32.7 \mu \mathrm{C} / \mathrm{cm}^{2}$ and $59 \mathrm{kV} / \mathrm{cm}$, respectively. The principal parameters obtained are listed in Table III. These results indicated that the PZT thin film has some amount of imprint and that the remanent polarization value was not so large compared to an epitaxial PZT film, for example that deposited by chemical vapor deposition. The self-alignment of the poling direction was from the surface to the bottom electrode, and this direction matches that of the polycrystalline PZT on titanium substrate. This automatic polarization is probably related to the imprint of the hysteresis curve. A similarly shaped hysteresis loop has previously been reported, and such imprint characteristics are probably in accordance with the $\mathrm{SrRuO}_{3}$ electrode. Guerrero et al. clarified the imprint phenomenon with Schottky barriers at the interface between electrode and PZT. ${ }^{16}$ Their model can probably be applied to PZT thin film, although this is still being investigated because the work function of the current PZT thin film remains unclear.

Observation of the current PZT thin film revealed that the film consisted of unity ferroelectric material and has no secondary phase, as shown in Fig. 10. The poling direction was totally aligned from the surface to the bottom, matching the results of the hysteresis curve. This self-alignment during the deposition process must be related to the imprint properties and the deposition mechanisms.

\section{CONCLUSIONS}

In addition to overcoming the peel-off problem, PZT deposition on the conductive perovskite bottom electrode was confirmed. Among the various parameters for hydrothermal deposition, substrate depth in the solution was confirmed to be important to obtain smooth morphology. As a bottom electrode, epitaxial $\mathrm{SrRuO}_{3}$ thin film was deposited on $\mathrm{SrTiO}_{3}$ (100) and (111) by rf magnetron sputtering. A PZT thin film was then deposited on $\mathrm{SrRuO}_{3}$ by a hydrothermal method. With these improvements, the ferroelectric properties of a hydrothermal epitaxial PZT could be measured for the first time. It is worth noting that the drying temperature did not exceed $200{ }^{\circ} \mathrm{C}$ for this PZT thin film. To the best of our knowledge, $150{ }^{\circ} \mathrm{C}$ is the lowest temperature for PZT deposition, and the hydrothermal method is the only method that enables deposition of PZT far below Curie temperature.

This is the first report of such a measurement about ferroelectric properties of hydrothermally deposited PZT thin film. From the SNDM measurement, the poling direction was found to be aligned with the surface of the bottom electrode. This tendency matches that of the hydrothermal polycrystalline PZT on titanium substrate. This self-poling alignment is probably related to the deposition mechanism and energy band difference at the interface between the PZT and both electrodes.

\section{REFERENCES}

1. T. Morita: Miniature piezoelectric motor. Sens. Actuators 103, 291 (2003).

2. N. Ledermann, P. Muralt, J. Baborowski, S. Gentil, K. Mukati, M. Cantoni, A. Seifert, and N. Setter: $\{100\}$-Textured, piezoelectric $\mathrm{Pb}\left(\mathrm{Zr}_{\mathrm{x}}, \mathrm{Ti}_{1-\mathrm{x}}\right) \mathrm{O}_{3}$ thin films for MEMS: Integration, deposition and properties. Sens. Actuators, A 105, 162 (2003). 
3. C. Guerrero, J. Roldan, C. Ferrater, M.V. Garcia-Cuenca, F. Sanchez, and M. Varela: Growth and characterization of epitaxial ferroelectric $\mathrm{PbZr}_{\mathrm{x}} \mathrm{Ti}_{1-\mathrm{x}} \mathrm{O}_{3}$ thin film capacitors with $\mathrm{SrRuO}_{3}$ electrodes for non-volatile memory applications. Solid-State Electron. 45, 1433 (2001).

4. J.H. Kim, Y. Kim, A.T. Chien, and F.F. Lange: Epitaxial growth of $\mathrm{PbZr}_{0.5} \mathrm{Ti}_{0.5} \mathrm{O}_{3}$ thin films on $\mathrm{SrRuO}_{3} / \mathrm{SrTiO}_{3}$ substrates using chemical solution deposition: Microstructural and ferroelectric properties. J. Mater. Res. 16, 1739 (2001).

5. T. Oikawa T, M. Aratani, K. Saito, and H. Funakubo: Composition dependence of ferroelectric properties of epitaxial $\mathrm{Pb}\left(\mathrm{Zr}_{\mathrm{x}} \mathrm{Ti}_{1-\mathrm{x}}\right) \mathrm{O}_{3}$ thin films grown by metalorganic chemical vapor deposition. J. Cryst. Growth 237, 455 (2002).

6. I. Kanno, H. Kotera, K. Wasa, T. Matsunaga, T. Kamada, and R. Takayama: Crystallographic characterization of epitaxial $\mathrm{Pb}\left(\mathrm{Zr}_{\mathrm{x}} \mathrm{Ti}_{1-\mathrm{x}}\right) \mathrm{O}-3$ films with different $\mathrm{Zr} / \mathrm{Ti}$ ratio grown by radiofrequency-magnetron sputtering. J. Appl. Phys. 93, 4091 (2003).

7. K. Shimomura, T. Tsurumi, Y. Ohba, and M. Daimon: Preparation of lead zirconate titanate thin-film by hydrothermal method. Jpn. J. Appl. Phys. 30, 2174 (1991).

8. T. Morita, T. Kanda, Y. Yamagata, M.K. Kurosawa, and T. Higuchi: Single process to deposit PZT thin film by hydrothermal method. Jpn. J. Appl. Phvs. 36, 2998 (1997).

9. T. Morita, M.K. Kurosawa, and T. Higuchi: Cylindrical micro ultrasonic motor using PZT thin film deposited by single process hydrothermal method $(\phi 2.4 \mathrm{~mm}$, L10mm Stator Transducer). IEEE Trans. Ultrasonic, Ferroelectrics, and Frequency Control 45, 1178 (1998).
10. T. Morita, M.K. Kurosawa, and T. Higuchi: A cylindrical shaped micro ultrasonic motor utilizing PZT thin film. Sens. Actuators 83, 225 (2000)

11. T. Kanda, T. Morita, M.K. Kurosawa, and T. Higuchi: Estimation of resolution and contact force of a longitudinally vibrating touch probe sensor using PZT thin-film vibrator. Jpn. J. Appl. Phys. 40, 3646 (2001).

12. A.T. Chien, J.S. Speck, and F.F. Lange: Hydrothermal synthesis of heteroepitaxial $\mathrm{Pb}\left(\mathrm{Zr}_{\mathrm{x}} \mathrm{Ti}_{1-\mathrm{x}}\right) \mathrm{O}_{3}$ thin film at 90-150. J. Mater. Res. 12, 1176 (1997).

13. M. Oledzka, M.M. Lencka, P. Pinceloup, K. Mikulka-Bolen, L.E., McCandlish, and R.E. Riman: Influence of precursor on microstructure and phase composition of epitaxial hydrothermal $\mathrm{PbZr}_{0.7} \mathrm{Ti}_{0.3} \mathrm{O}_{3}$ films. Chem. Mater. 15, 1090 (2003).

14. K. Takahashi, T. Oikawa, K. Saito, S. Kaneko, H, Fujisawa, M. Shimizu, and H. Funakubo: Effect of strain in epitaxially grown $\mathrm{SrRuO}_{3}$ thin films on crystal structure and electric properties. Jpn. J. Appl. Phys. 41, 5376 (2002).

15. Y. Cho, S. Kazuta, and K. Matsuura: Scanning nonlinear dielectric microscopy with nanometer resolution. Appl. Phys. Lett. 75, 2833 (1999).

16. C. Guerrero, J. Roldan, C. Ferrater, M.V. Garcia-Cuenca, F. Sanchez, and M. Varela: Growth and characterization of epitaxial ferroelectric $\mathrm{PbZr}_{\mathrm{x}} \mathrm{Ti}_{1-\mathrm{x}} \mathrm{O}_{3}$ thin film capacitors with $\mathrm{SrRuO}_{3}$ electrodes for non-volatile memory applications. Solid-State Electronics 45, 1433 (2001). 